М. М. Дивизинюк, д.ф.-м.н., проф., заместитель директора по научной работе e-mail: divizinyuk@ukr.net

Государственное учреждение «Институт геохимии окружающей среды», Национальная академия наук Украины пр. Палладіна, 34а, г. Киев, Украина, 03680

О. Н. Мирошник, к.т.н., дои., заместитель начальника кафедры пожарной тактики и аварийно-спасательных работ e-mail: omiroshnik@ukr.net

Черкасский институт пожарной безопасности им. Героев Чернобыля НУГЗ Украины вул. Оноприенка, 8, г. Черкассы, Украина, 18034

А. Самберг, директор Миссии международной организации по управлению чрезвычайными ситуациями TIEMS в Украине e-mail: info@tiemsukr.org

Pl 180, Helsinki, Finland, 00701

\title{
МАТЕМАТИЧЕСКАЯ МОДЕЛЬ ОБНАРУЖЕНИЯ И ИДЕНТИФИКАЦИИ РАЗЛИВОВ НЕФТЕПРОДУКТОВ НА ВОДНОЙ ПОВЕРХНОСТИ
}

В статье рассматривается математическая модель выявления и идентификации разливов нефтепродуктов на водной поверхности, состоящая из пяти зависимостей, первые три из которых определяют дальность выявления антропогенного разлива нефтепродуктов на водной поверхности в зависимости от конкретных условий постановки задания поиска антропогенных загрязнений на водной поверхности летательным аппаратом, оборудованным лидаром, а две следующие зависимости описывают процесс идентификации обнаруженного пятна и определения его происхождения.

Ключевые слова: математическая модель, разлив нефтепродуктов, лидар, нефтяное пятно, идентификация.

Введение. Три четверти Земной поверхности составляет акватория Мирового океана, которая определяет главную климатическую составляющую окружающей (земной) природной среды [1]. Влияние негативных техногенных факторов и их антропогенных последствий вызывает изменения в окружающей природной среде, которые в большинстве случаев проявляются в форме различных чрезвычайных ситуаций и катастроф $[2,3]$. Один из тяжелейших видов чрезвычайных ситуаций техногенного характера, происходящих в морях и океанах, обусловлен разливом нефтепродуктов [4]. Их последствия воздействуют на флору и фауну не только прибрежных вод и побережья, находящихся в непосредственной близости от места происшествия, но и распространяются на сотни километров в течение ближайших дней после аварии. Часть разлитых нефтепродуктов переходит в эмульгированное состояние и мигрирует в водной толще невидимо для человеческого глаза, загрязняя районы, где их появления никто не ожидает [5].
Предотвращение такого рода чрезвычайных ситуаций - это актуальнейшая многоплановая проблема, решением которой занимаются не только специальные государственные службы и ведомства, но и широкий круг ученых, обеспечивающих как прикладные, так и фундаментальные научные исследования $[6,7]$.

Постановка цели и задач научного исследования. Цель данной работы - разработать математическую модель обнаружения и идентификации разливов нефтепродуктов на водной поверхности с использованием авиационного активного гиперспектрального сканирующего лидара.

Для достижения поставленной цели необходимо решить ряд научных задач, а именно: дать описание физических процессов обнаружения антропогенных нефтяных загрязнений на водной поверхности с использованием активного гиперспектрального сканирующего лидара; рассмотреть процесс идентификации нефтяных пятен и определения их происхождения (определения источника 
умышленного сброса); описать полученную математическую модель.

Характеристика физических процессов обнаружения антропогенных нефтяных загрязнений на водной поверхности. Процесс обнаружения антропогенных нефтяных загрязнений лидаром определяется его основными техническими характеристиками. К ним относятся коэффициент распознавания $\delta$ приемной оптической системы, чувствительность приёмного регистрирующего устройства $P_{n p}$, коэффициент усиления оптической системы $K_{y c}$, мощность излучения лазерного импульсного сигнала $P_{u}$

Главной характеристикой облучаемого объекта является радиус эквивалентной отражающей поверхности $R_{\text {э }}$. Эта величина определяет зернистость облучаемого лазерным лучом объекта и зависит от его молекулярной массы. Поэтому радиусы эквивалентной отражающей поверхности для керосинов и других легких нефтепродуктов будут меньшими по сравнению с радиусами эквивалентной отражающей поверхности дизельного топлива, машинных масел и сырой нефти.

Кроме того, для одного и того же вида нефтепродукта радиус эквивалентной отражающей поверхности будет зависеть от термобарических параметров приводного слоя атмосферы и термохалинных характеристик приповерхностного слоя морских вод. Совокупность этих величин принято также называть энергетическим потенциалом средства обнаружения по определённому объекту или классу объектов (антропогенных загрязнений), которая обозначается $\Pi_{э c o}$.

Закономерность спада интенсивности распространяющейся световой (электромагнитной) волны $\Psi(Д, f)$ - это математическая зависимость, характеризующая закономерность затухания любой распространяющейся волны за счёт расширения сферического фронта и объёмного затухания. Последнее зависит от частоты излучения, которая является фиксированной величиной для определённого класса оптических средств обнаружения, в том числе и для рассматриваемого образца.

Допуская, что основные параметры лидара остаются неизменными, то есть режим его работы не изменяется в течение времени поиска антропогенных загрязнений на водной поверхности, энергетический потенциал можно рассматривать как функцию, зависящую от свойств отражающей поверхности объекта обнаружения, то есть $\Pi_{э с о}\left(R_{э}\right)$ зависит от радиуса эквивалентной отражающей поверхности. Отсюда следует, что энергетическая дальность обнаружения объекта (антропогенного загрязнения на водной поверхности) определяется соответствием (равенством) значения энергетического потенциала средства оптического обнаружения значению закономерности спада интенсивности распространяющейся световой (электромагнитной) волны, рассчитанному для дистанции, то есть

$$
Д_{э}=f\left[\Psi(Д, f) ; \Pi_{э с о}\left(R_{\ni}\right)\right\rfloor
$$

Энергетическая дальность обнаружения $Д_{9}$ является расчётной или аналитической величиной, которая не учитывает искривление земной поверхности, обусловленное её формой, особенностей раскрыва оптических устройств, установленных на летательном аппарате, и способов сканирования водной поверхности. Все это учитывает геометрическая дальность обнаружения объектов, которая определяется дальностью видимого горизонта $Д_{л 2}$, учитывающей высоту полета летательного аппарата $h_{A}$, текущим значением азимута $\alpha$, определяющего разворот оптического устройства на угол относительно направления на север, и функционалом $F_{p \alpha}$, оценивающим положение сканирующего лазерного луча по $i$-тому направлению, задаваемому азимутом разворота оптического устройства обнаружения. То есть геометрическая дальность обнаружения загрязнений имеет вид:

$$
Д_{\Gamma}=\varphi\left(Д_{n 2}, \alpha, F_{p \alpha}\right)
$$

Однако геометрическая дальность обнаружения объекта Д г не учитывает прохождение световых волн через воздушную среду, определяемую состоянием приземных слоёв атмосферы.

Для этого используется ожидаемая дальность обнаружения объектов, учитывающая состояние приземных слоёв атмосферы, которое традиционно характеризуется температурой воздуха, его влажностью, атмосферным давлением и наличием естественных (туман, морось, снегопад) и искусственных (дым, огонь, вызванный пожаром, пар, обусловленный аварией на теплотрассе) примесей. 
Поскольку каждый из этих параметров в каждой точке окружающего воздушного пространства имеет своё значение, то гидрометеорологами принято говорить о поле температуры, поле влажности, поле атмосферного давления и поле распространяющейся примеси. Каждое из перечисленных полей представляет собой совокупность значений единого параметра, распределенного с заданной дискретностью в рассматриваемом объёме приземного пространства.

Для получения информации об оптических свойствах атмосферы, их временной и пространственной изменчивости наряду со специальными спектрометрическими измерениями используются данные стандартных сетевых актинометрических наблюдений. По измерениям энергетической яркости прямой солнечной радиации рассчитывается интегральный коэффициент прозрачности атмосферы. Кроме коэффициента прозрачности могут использоваться коэффициент ослабления, коэффициент мутности и другие.

В ряде случаев при использовании широкополосных сигналов возникает необходимость учета характеристики спектральной прозрачности атмосферы. Если в пределах спектрального интервала коэффициент ослабления нельзя считать постоянным, то при лазерном зондировании необходимо использовать не спектральную прозрачность атмосферы, а функцию пропускания, искаженную действием аппаратурной функции источника.

Одним из существенных показателей прозрачности атмосферы является облачность. Наличие облаков может полностью исключить использование авиационных лидаров для зондирования водной поверхности. Поэтому для практических расчетов функции пропускания лазерного излучения нижними слоями атмосферы существует множество эмпирических методик расчета коэффициентов ослабления по данным температуры, влажности, давления, силы ветра и соответствующим диапазонам излучаемых волн. В ряде методик это ослабление называют коэффициентом аномалии $A$ нижних слоев атмосферы. Заметим, что существуют методики для определения коэффициента аномалии по ряду местных региональных признаков.

Геометрическая дальность обнаружения объекта, умноженная на коэффициент аномалии $A$ нижних слоев атмосферы, носит назва- ние ожидаемой дальности обнаружения объекта.

В ряде случаев для определения ожидаемой дальности обнаружения используют не геометрическую, а энергетическую дальность обнаружения. Это возможно, когда $Д_{э} \ll Д_{г}$. Поэтому для определения ожидаемой дальности используют выражение:

$$
Д_{0}=A \cdot\left\{\begin{array}{l}
Д_{\Gamma}, \text { если } Д_{\Gamma} \approx Д_{\ni} \\
Д_{\ni}, \text { если } Д_{\ni}<<Д_{\Gamma}
\end{array} .\right.
$$

\section{Описание процесса идентификации нефтяных пятен и определения их проис-} хождения. Идентификация, от латинского «identifico» - отождествление, установление тождественности неизвестного объекта известному образу на основании совпадения существенных признаков.

Антропогенные загрязнения, которые появляются в результате умышленного сброca, в своем большинстве вызваны различными видами нефтепродуктов: от летучих керосинов до сырой нефти. Чаще всего это смесь различных видов углеводородов, образованная в результате эксплуатационных протечек корабельных систем и перемешивания в трюмах водных транспортных средств, так называемые льяльные воды, которые чаще всего и сбрасываются как с океанских судов, так и с малых плавсредств.

Возможности лидаров позволяют производить обнаружение и определять месторасположение нефтяных пленок размерами от нескольких квадратных дециметров в штилевую погоду. Производя многочастотное сканирование обнаруженной нефтяной пленки лидаром можно получить ее фотометрический спектр. Сравнивая полученный лидарный фотометрический спектр со спектрами, имеющимися в базе данных, можно определить плавсредство, которое произвело умышленный сброс.

Другими словами, задача идентификации обнаруженного объекта технически сводится к оптимальной фильтрации принятых приемным устройством всех отраженных сигналов, поступающих как от обнаруженных антропогенных объектов, так и от образов, имеющихся в базе данных. Она решается методами оптимальной линейной фильтрации по критерию минимума среднего квадрата ошибки и линейной фильтрации по критерию 
правдоподобия - максимального отношения сигнал-шум.

В первом случае получаем, что спектральная плотность полученного сигнала при оптимальной линейной фильтрации по критерию минимума среднего квадрата ошибки определяется количеством типов (образов) принятых импульсных отражений от антропогенного загрязнения при её идентификации и описывается выражением:

$$
S_{s}(\omega)=f\left(N_{0}\right) \text {, }
$$

где $S_{s}(\omega)$ - спектральная плотность широкополосного сигнала;

$N_{0}$ - количестве типов (образов) нефтяных загрязнений, имеющихся в базе данных лидара.

Во втором случае спектральная плотность полезного сигнала при оптимальной линейной фильтрации по критерию правдоподобия - максимального отношения сигналшум, определяется степенью сопряжения (соответствия) амплитудно-частотной характеристики приёмного устройства амплитудному спектру входного полезного широкополосного сигнала и описывается выражением:

$$
S_{S}(\omega)=K^{S} \cdot S(j \omega) \text {, }
$$

где $K^{S}$ - функция, показывающая степень сопряжения (соответствия) коэффициента усиления в полосе приёмного устройства амплитудному спектру входного сигнала.

Объединяя в одну систему выражения (1)-(5), получим искомую математическую модель

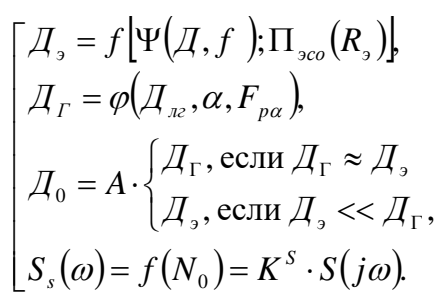

Выводы. Математическая модель обнаружения и идентификации разливов нефтепродуктов на водной поверхности позволяет получить расчетные значения энергетической, геометрической и ожидаемой дальностей обнаружения антропогенных загрязнений в зависимости от конкретных условий постановки задачи их поиска на водной поверхности с использованием летательного аппарата, оснащенного лидаром, и проводить их идентификацию по критерию минимума среднего квадрата ошибки и определение происхождения пятна по критерию правдоподобия - максимальному отношению сигнал-шум.

\section{Список литературы}

1. Шулейкин В. В. Физика моря. М.: Наука, 1967. 1086 c.

2. Азаренко Е. В. и др. Моделирование чрезвычайных ситуаций, вызванных нефтяным загрязнением на внутренних и внешних рейдах портов. Сб. науч. тр. СНУЯЭиП. Севастополь: СНУЯЭиП, 2009. Вып. 3 (31). С. 192-198.

3. Гончаренко Ю. Ю., Браславский Ю. В., Григорьева В. Н. Структурно-логическая модель развития чрезвычайной ситуации, вызванной разливом нефти. Сб. науч. тр. СНУЯЭиП. Севастополь: СНУЯЭиП, 2010. Вып. 4 (36). С. 222-227.

4. Азаренко Е. В., Дивизинюк М. М., Третьякова Л. В. Обнаружение эмульгированных нефтяных загрязнений в северозападной части Черного моря. Сб. науч. тр. СНИЯЭиП. Севастополь: СНИЯЭиП, 2004. Вып. 11. С. 155-162.

5. Азаренко Е. В., , Гончаренко Ю. Ю., Дивизинюк М. М. Модели распространения антропогенной примеси в Черном море: монография. Севастополь: Госокеанариум, 2012. 92 c.

6. Про цивільну оборону України: Закон України. Відомості Верховної Ради. 2007. № 33.

7. Международная конвенция по предотвращению загрязнения судов 1973 года и Протокол 1978 года. М.: Изд-во УРИА «Морфлот», 1980. 364 с.

\section{References}

1. Shuleykin, V. V. (1967) Fizika morya. Nauka. $1086 \mathrm{c}$.

2. Azarenko, E. V. i dr. (2009) Modelirovaniye chrezvychaynykh situatsiy, vyzvannykh neftyanym zagryazneniyem na vnutrennikh i vneshnikh reydakh portov. Sb. nauch. $t r$. SNUYAEiP. Sevastopol': SNUYAEiP. Vyp.3 (31). C. 192-198. 
3. Goncharenko, YU. YU., Braslavskiy, YU. V., Grigor'yeva, V. N. (2010) Strukturno-logicheskaya model' razvitiya chrezvychaynoy situatsii, vyzvannoy razlivom nefti. Sb. nauch. tr. SNUYAEiP. Sevastopol': SNUYAEiP. Vyp. 4 (36). C. 222-227.

4. Azarenko, E. V., Tret'yakova L. V., Divizinyuk, M. M. (2004) Obnaruzheniye emul'girovannykh neftyanykh zagryazneniy v severo-zapadnoy chasti Chernogo moray. Sb. nauch. tr. SNIYAEiP. Sevastopol': SNIYAEiP. Vyp. 11. C. 155-162.
5. Azarenko, E. V., Goncharenko, YU. YU., Divizinyuk, M. M. Modeli rasprostroneniya antropogennoy primesi v Chernom more: monografiya. Sevastopol': Gosokeanarium, 2012. 92 c.

6. Pro tsyvil'nu oboronu Ukrayiny: Zakon Ukrayiny (2007) Vidomosti Verkhovnoyi Rady. № 33.

7. Mezhdunarodnaya konventsiya po predotvrashcheniyu zagryazneniya sudov 1973 goda i Protokol 1978 goda. M.: Izd-vo URIA «Morflot», 1980. 364 c.

M. Diviziniuk, Doctor of Physical and Mathematical Sciences, Professor, the defender of the director of science robotics e-mail: divizinyuk@ukr.net

State institution «Institute of Environmental Geochemistry of the National Academy of Sciences of Ukraine»

34, Palladin Avenue, Kyiv, Ukraine

O. Miroshnik, candidate of science (Hist.), docent docent of fire tactics and emergency-rescuer activities e-mail: omiroshnik@ukr.net

Cherkasy Institute of Fire Safety named after Chornobyl Heroes of National University of Civil Protection of Ukraine,

Onoprienko Str.8, Cherkasy, Ukraine, 18034

A. Samberg, Head The International Emergency Management Society, Tiems Mission to Ukraine e-mail: info@tiemsukr.org

Pl 180, Helsinki, Finland, 00701

\section{MATHEMATICAL MODEL OF DETECTION AND IDENTIFICATION SPREADS OF OIL PRODUCTS ON WATER SURFACE}

The article considers a mathematical model for the detection and identification of oil spills on the water surface, which consists of five relationships, the first three of which determine the detection range of anthropogenic spillage of oil products on the water surface, depending on the specific conditions for setting an anthropogenic pollution problem on the water surface with an aircraft equipped with lidar, and two subsequent dependencies describe the process of identifying the detected spot and determining its origin walking.

Keywords: mathematical model, oil spill, lidar, oil slick, identification.

Стаття надійшла 15.05.2018.

Статтю представляє М. М. Дівізінюк, д.ф.-м.н., професор. 